\title{
PENGARUH E-MARKETING SEBAGAI MEDIA PROMOSI POTENSI PARIWISATA ERA REVOLUSI INDUSTRI 4.0 DI SAUNG ANGKLUNG UDJO
}

\author{
Nurul Rochmah Pramadika ${ }^{1}$, Rusdin Tahir $^{2}$, Awaludin Nugraha ${ }^{3}$ Heryadi Rachmat ${ }^{4}$, Ute Lies Siti Khadijah ${ }^{5}$ \\ 1,2,3,4,5 Sekolah Pascasarjana, Universitas Padjadjaran, Jl. Dipati Ukur No. 35 Kota Bandung, 40132 \\ Program Studi Magister Pariwisata Berkelanjutan \\ e-mail: Nurul19004@mail.unpad.ac.id; rusdin@unpad.ac.id; Awaludin.nugraha@unpad.ac.id; \\ heryadirachmat220@gmail.com; ute.lies@unpad.ac.id
}

\begin{abstract}
ABSTRAK
Revolusi industri 4.0 merupakan fenomena yang mengkolaborasi antara teknologi cyber dengan konsep penerapannya tidak memerlukan tenaga kerja manusia dalam aplikasi prosesnya. Pemasaran di dunia bisnis pariwisata dengan menggunakan teknologi akan sangat membantu penyedia jasa memberikan gambaran produk terhadap calon klien mereka. Digitalisasi media yang digunakan dalam kegiatan pemasaran ini harus dilakukan secara efesien dan efektif, oleh karena itu dalam penelitian ini e-marketing diangkat sebagai topik karena dinilai sebagai salah satu cara aksi pemasaran yang dapat membantu berperan dalam promosi pariwisata. Dengan bermunculan atraksi dan daya tarik wisata yang baru dan menarik di kota Bandung, apakah akan berdampak pada motivasi kunjungan wisatawan ke Saung Angklung Udjo. Maka dari itu penulis mengidentifikasi daya tarik wisata yang terdiri dari potensi. EMarketing membantu dalam memberikan gambaran potensi pariwisata kepada wisatawan baik mancanegara maupun domestik
\end{abstract}

Kata kunci; E-Marketing, digitalisasi, teknologi, potensi

\section{THE INFLUENCE OF E-MARKETING AS PROMOTION MEDIA OF TOURISM POTENTIAL AT INDUSTRIAL 4.0 REVOLUTION IN SAUNG ANGKLUNG UDJO}

\begin{abstract}
Industrial revolution 4.0 is a phenomenon that collaborates between cyber technology and the concept of its application does not require human labor in the application process. Marketing in the tourism business is using technology will greatly help service providers provide an overview of products to their prospective clients. The digitalization of the media used in marketing activities must be done efficiently and effectively, therefore in this research of e-marketing was raised as a topic because it was considered as one of the ways of marketing action that can help in tourism promotion. With the presence new tourist attraction and interesting in Bandung, whether it will have an impact on the tourists motivation to visit Saung Angklung Udjo. Therefore the authors identify the tourist attraction that consists of potential. The E-Marketing helps in providing a description of the potential of tourism to both foreign and domestic tourists.
\end{abstract}

Key words; E-Marketing, digitalization, technology, potential

\section{PENDAHULUAN}

Fenomena era revolusi industri 4.0 sudah tidak asing lagi saat ini. Perkembangan pesat teknologi dan informasi yang terjadi di dunia sudah dirasakan oleh hampir seluruh lapisan masyarakat, termasuk di Indonesia. Hal tersebut menambah efisiensi pada suatu lingkungan kerja dimana manajemen waktu yang baik berdampak secara nilai pada kualitas tenaga kerja dan biaya produksi. Big data adalah istilah yang paling berperan dalam era revolusi industri 4.0 ini. Volume data yang besar, baik data yang terstruktur maupun data yang tidak terstruktur dapat menentukan arah bisnis. Digitalisasi di era globalisasi ini merupakan sebuah inovasi. Ionescu dan Dumitri menyebutkan bahwa inovasi dapat menghasilkan 
produk berkualitas, layanan yang unggul, proses efisien, perbaikan sistem manajemen dan penerapan yang lebih modern. Vlachos (2013) menambahkan bahwa proses bisnis elektronik menjadi saluran komunikasi utama untuk mengakses pelanggan dan menemukan pelanggan baru serta menjaga hubungan berkelanjutan yang sudah ada.

Dari fenomena revolusi industri 4.0 yang terjadi, ada dampak dalam aspek kehidupan termasuk di bidang pariwisata. Kemajuan teknologi memberikan peluang bagi bisnis pariwisata untuk menemukan saluran komunikasi utama dalam menyampaikan informasi kepada pelanggannya. Rachmawati (2011) mengutarakan bahwa pemasaran adalah tahap penyusunan komunikasi terpadu dengan tujuan untuk memberikan informasi mengenai barang ataupun jasa agar dapat memuaskan kebutuhan serta keinginan manusia. Pemasaran diawali dengan pemenuhan kebutuhan manusia yang kemudian berkembang menjadi keinginan manusia. Tahap dalam pemenuhan kebutuhan serta keinginan manusia inilah yang menjadi konsep pemasaran. Setelah mengetahui secara umum tinjauan dari pemasaran pembahasan selanjutnya adalah mengenai promosi, karena promosi merupakan fokus dari penelitian ini. Kotler (2012) mengartikan promosi sebagai berbagai macam cara yang ditempuh perusahaan dalam rangka menjual produk ke konsumen atau berbagai kegiatan perusahaan untuk mengkomunikasikan dan memperkenalkan produk pada pasar sasaran. Berdasarkan pengertian tersebut dapat disimpulkan bahwa promosi adalah kegiatan komunikasi informasi yang bertujuan untuk memperkenalkan produk kepada pasar sasaran sehingga terjadi pembelian.

Pembahasan selanjutnya adalah mengenai emarketing yang akan menunjang penelitian ini. Kienan (dalam Mardiani danImanuel, 2013) mengatakan, "E - marketing adalah melakukan bisnis online yang bentuknya paling jelas adalah menjual produk kepada konsumen secara online. Sederhananya adalah membuat, mengelola dan meluaskan hubungan komersial secara online.” Bordonaba dkk (2012) menambahkan bahwa bisnis secara elektronik akan menciptakan operasional yang efisien dan meningkatkan pencapaian perusahaan.

Wolah (2016) menyebutkan bahwa di era sekarang ini dengan kemajuan teknologi informasi maka perkembangan semua bidang dapat berjalan dengan baik dan lancar, termasuk juga bidang kepariwisataan dapat dikembangkan secara cepat dengan adanya teknologi informasi sehingga informasi dapat diterima dengan efektif dan aktual. Pengembangan kepariwisataan dibutukan teknologi informasi yang dapat membantu penyampaian informasi mengenai promosi pariwisata dapat dikenal dengan cepat dan meluas ke seluruh dunia.

\section{METODE}

Dalam penelitian ini penulis menggunakan metode penelitian kuantitatif karena dinilai akan memberikan hasil yang lebih objektif dan lebih terukur mengenai objek yang diteliti. Teknik pengumpulan data yang digunakan untuk penelitian ini adalah data primer dan data sekunder. Sampel di dalam penelitian ini penulis menggunakan teknik Quota Sampling. Teknik pengambilan sampel dalam penelitian ini adalah dengan menggunakan metode non probability sampling. Menurut Sugiyono (2007) non probability sampling merupakan teknik pengambilan sampel yang tidak memberi kesempatan sama bagi setiap unsur populasi yang akan dipilih sebagai sampel. Sementara untuk jenis sampel menggunakan judgment sampling atau pengambilan sampel keputusan. Menurut Sunyoto (2012) pengambilan jenis sampel judgment sampling 
terjadi ketika seorang peneliti menentukan dan memilih anggota-anggota sampel yang dapat menyesuaikan diri dengan beberapa kriteria.

\section{HASIL DAN PEMBAHASAN}

Hipotesis yang diajukan dalam penelitian ini adalah sebagai berikut :

20 : Tidak terdapat pengaruh antara e-marketing terhadap potensi promosi pariwisata di Saung Angklung Udjo.

: Terdapat pengaruh antara e- marketing terhadap potensi promosi pariwisata di Saung Angklung Udjo.

Variabel yang digunakan dalam penelitian ini adalah variabel bebas dan variabel terikat.

a. Variabel Bebas (Independent Variable)

Variabel bebas adalah variabel yang mempengaruhi, yang menyebabkan timbulnya atau berubahnya variabel terikat. Variabel bebas yang digunakan dalam penelitian ini adalah e-marketing.

b. Variabel Terikat (Dependent Variable)

Variabel terikat adalah variabel yang dipengaruhi karena adanya variabel bebas. Variabel terikat yang digunakan dalam penelitian ini adalah potensi promosi pariwisata.

Berikut adalah analisis deskriptif dimensi dari potensi yang dimiliki oeh Saung Angklung Udjo. Potensi tersebut dapat tergambar secara visual dari EMarketing yang disajikan dalam website maupun media sosial Saung Angklung Udjo.

\section{Hasil Analisis Deskriptif Dimensi}

Potensi 3,73. Hal itu menunjukan bahwa responden setuju dengan pernyataan yang menyebutkan bahwa Suasana Angklung Udjo tenang.
Meskipun lokasi Saung Angklung Udjo berada di samping jalan raya, wisatawan merasa tenang ketika berada di Saung Angklung Udjo dikarenakan lingkungannya di penuhi oleh tumbuh-tumbuhan dan pepohonan yang rimbun,.

Pernyataan suasana Saung Angklung Udjo nyaman menunjukan hasil mean 4,06. Hal ini menunjukkan bahwa wisatawan setuju dengan pernyataan yang menyebutkan bahwa suasana Saung Angklung Udjo nyaman. Selain menimbulkan rasa tenang, tumbuh-tumbuhan dan pepohonan yang berada di sekitar Saung Angklung Udjo membuat suasana dan udara di Saung Angklung Udjo sejuk dan asri serta sarana pendukung yang tersedia bagi wisatawan membuat wisatawan merasa nyaman ketika berada di lingkungan Sang Angklung Udjo.

Secara keseluruhan dimensi potensi memiliki nilai rata-rata 3,89 , yang berarti bahwa potensi yang dimiliki Saung Angklung Udjo baik. Wisatawan merasakan kenyamanan dan ketenangan ketika berada di Saung Angklung Udjo.

\begin{tabular}{|c|c|c|c|}
\hline Pernyataan & Mean & $\begin{array}{c}\text { Kete } \\
\text { rangan }\end{array}$ & $\begin{array}{c}\text { Std } \\
\text { Deviasi }\end{array}$ \\
\hline $\begin{array}{c}\text { Suasana Saung } \\
\text { Angklung Udjo } \\
\text { tenang }\end{array}$ & 3,73 & Setuju & 888 \\
\hline $\begin{array}{c}\text { Suasana Saung } \\
\text { Angklung Udjo } \\
\text { nyaman }\end{array}$ & 4,06 & Setuju & 781 \\
\hline $\begin{array}{c}\text { Total } \\
\text { Rata-Rata }\end{array}$ & 3,89 & Setuju & \\
\hline
\end{tabular}

Sumber: Hasil Olahan Penulis (2015)

Dari tabel penyataan suasana Saung Angklung Udjo tenang menunjukan hasil mean

\section{SIMPULAN}

Hasil penelitian mengenai e-marketing di era revolusi 4.0 merupakan realita yang berpengaruh dalam dunia kepariwisataan. Smart tourism bukan hanya mengandalkan teknologi saja, melainkan 
kemampuan SDM menggunakan teknologi terkini untuk menjalankan bisnis dalam kegiatan promosi. Inovasi adalah hal yang diperlukan dalam kegiatan pemasaran agar tercapainya produk unggulan yang dapat menarik minat konsumen untuk berwisata di sebuah destinasi. Dari lokasi penelitian yang diambil oleh penulis. Daya tarik ini banyak dikunjungi oleh wisatawan mancanegara. Mereka tertarik dengan suasana dengan penuh nilai budaya yang tersajikan di Saung Angklung Udjo. Penggunaan E- Marketing membantu pengelola memberikan gambaran secara visual melalui akses digital dengan waktu yang efektif dan efisien secara global.

\section{DAFTAR PUSTAKA}

Bordonaba, J.V., Palacios, L.L dan Redondo, P.Y. 2012). The Influence of organizational factors on E-business

use: analysis of firm size. Marketing Intelligence and Planning, Vol.30, No.2

Ionescu, A dan Dumitri, N.R. (2015). The role of innovation in creating the company's competitive advantage. Ecoforum Journal, Vol.4, No 6.

Kotler, P \& Armstrong, G. (2012). Prinsip - prinsip Pemasaran Edisi ke-12 jilid 2. Jakarta: Erlangga.

Mardiani, I. Endang dan Orland, J. Imanuel. (2013). Analisis Keputusan Pembelian Konsumen Melalui Media Online (E- Marketing). Jurnal Ekonomi, Volume 4 Nomor 2, November.
Rachmawati, R. (2011). Peranan Bauran Pemasaran (Marketing Mix) terhadap Peningkatan Penjualan (Sebuah Kajian terhadap Bisnis Restoran). Judul Jurnal: Jurnal Kompetensi Teknik, Vol. 2, No. 2, Mei 2011.

Sugiyono. (2007). Statistik untuk Penelitian. Bandung: Alfabeta.

Sunyoto, D. (2012). Konsep Dasar Riset Pemasaran Perilaku Konsumen. Jakarta: CAPS (Center for Academic Publishing Service).

Vlachos, I.P. (2013). Investigating e-business practices in tourism: a comparative analysis of three countries. Tourismos: an International Multidisciplinary Journal of Tourism, Vol.8, No.1.

Wolah, Ferny.F.Ch. (2016). Peranan Promosi Dalam Meningkatkan Kunjungan Wisatawan di Kabupaten Poso. e- journal "Acta Diurna" Volume V. No.2 